\title{
约 \\ INVISIBILIADADE OU ANACRONISMO FAMILIAR? REPRESENTAÇÕES SOCIAIS DE FAMÍLIA NO ESTATUTO DA FAMÍLIA (PL 6583/2013)
}

\author{
INVISIBILITY OR FAMILY ANACRONISM? FAMILY SOCIAL \\ REPRESENTATIONS IN THE FAMILY STATUTE (PL 6583/2013)
}

\begin{abstract}
¿INVISIBILIDAD O ANACRONISMO FAMILIAR? REPRESENTACIONES SOCIALES DE LA FAMILIA EN EL ESTATUTO DE LA FAMILIA (PL 6583/2013)
\end{abstract}

\author{
Weverton Fernandes Bento Alves ${ }^{1}$ \\ Daniela Leandro Rezende ${ }^{2}$
}

\begin{abstract}
Resumo: A família consiste em uma construção social, variável com o tempo, o contexto histórico e as mudanças sociais. Porém, o Projeto de Lei 6583 de 2013 (PL 6583/2013) visa instituir o Estatuto da Família no ordenamento jurídico brasileiro e reconhece apenas a união nuclear heterossexual e monogâmica como família e estigmatiza os demais arranjos familiares. Este artigo, amparado na Teoria das Representações Sociais, por meio da revisão bibliográfica e da análise documental, analisou a redação original e a justificativa do PL 6583/2013 e constatou-se que a representação social de família nesta proposição consiste em uma ideologia da frente parlamentar evangélica na Câmara dos Deputados. Concluiu-se, portanto, que a finalidade do PL 6583/2013 é a tentativa de reafirmação da família enquanto instituição "natural" e funciona como um mecanismo de controle de comportamentos sociais.
\end{abstract}

Palavras-chave: Família; Representações Sociais; PL 6583/2013; Estatuto da Família.

Abstract: The family consists of a social construction, variable over time, the historical context and social changes. However, Bill 6583 of 2013 (PL 6583/2013) aims to institute the Family Statute in the Brazilian legal system and recognizes only the heterosexual and monogamous nuclear union as a family and stigmatizes other family arrangements. This article, supported by the Theory of Social Representations, through bibliographic review and documentary analysis, analyzed the original wording and justification of PL 6583/2013 and found that the social representation of the family in this proposition consists of a front ideology evangelical parliamentarian in the Chamber of Deputies. It was concluded, therefore, that the purpose of PL 6583/2013 is the attempt to reaffirm the family as a "natural" institution and works as a mechanism for controlling social behaviors.

Keywords: Family; Social Representations; PL 6583/2013; Family Statute.

Resumen: La familia consta de una construcción social, variable en el tiempo, el contexto histórico y los cambios sociales. Sin embargo, el Proyecto de Ley 6583 de 2013 (PL 6583/2013) tiene como objetivo

\footnotetext{
${ }^{1}$ Mestrando em Família e Sociedade no Programa de Pós-Graduação em Economia Doméstica da Universidade Federal de Viçosa (UFV). Especialista em Direito da Família pela Universidade Candido Mendes (UCAM). Bacharel em Direito pela Faculdade Mineira de Direito da Pontifícia Universidade Católica de Minas Gerais (PUC Minas). Foi Professor orientador do Núcleo de Estudos Avançados em Direito Civil da Liga Acadêmica Jurídica de Minas Gerais (LAJUMG), vinculada à PUC Minas, nos anos de 2018 e 2019. Mediador formado pela Escola Judicial Desembargador Edésio Fernandes (EJEF) do Tribunal de Justiça de Minas Gerais (TJMG). Advogado e Consultor Jurídico em Minas Gerais. ORCID: https://orcid.org/0000-0002-0293-5112 E-mail: wevertonfba@ gmail.com

${ }^{2}$ Graduação em Ciências Sociais, mestrado e doutorado em Ciência Política pela Universidade Federal de Minas Gerais. Integra o Núcleo de Estudos de Violência e Direitos Humanos (NEVIDH/UFJF), o Núcleo Interdisciplinar de Estudos de Gênero (NIEG/UFV) e o Grupo Brasileiro de Estudos sobre Cannabis (GBEC/UFV). Atualmente é professora no Departamento de Ciências Administrativas da Universidade Federal de Ouro Preto.
} 
instituir el Estatuto de Familia en el sistema legal brasileño y reconoce solo la unión nuclear heterosexual y monógama como familia y estigmatiza otros arreglos familiares. Este artículo, apoyado en la Teoría de las Representaciones Sociales, mediante revisión bibliográfica y análisis documental, analizó la redacción y justificación original de la PL 6583/2013 y encontró que la representación social de la familia en esta proposición consiste en una ideología de fachada parlamentaria evangélica en el Cámara de Diputados. Se concluyó, por tanto, que el propósito de la PL 6583/2013 es el intento de reafirmar a la familia como institución "natural" y funciona como mecanismo de control de las conductas sociales.

Palabras clave: Familia; Representaciones sociales; PL 6583/2013; Estatuto de Familia.

\section{Introdução}

No ordenamento jurídico brasileiro, lei, em sentido amplo, diz respeito aos atos normativos previstos no processo legislativo, contidos no artigo 59, incisos I a VII, da Constituição da República Federativa do Brasil de 1988 (CRFB/88), e compreendem emendas à Constituição, leis complementares, leis ordinárias, leis delegadas, medidas provisórias, decretos legislativos e resoluções. Nesses termos, lei consiste em um texto oficial de normas de observância geral, cuja função é de ordenar, regular e proteger os indivíduos na vida em sociedade pelo Estado e "destinam-se primariamente a funcionar como elementos estabilizadores para os movimentos do homem, que são eternamente mutáveis" (ARENDT, 2012, p. 515).

O Brasil adota o sistema legislativo bicameral no nível federal, ou seja, o "Poder Legislativo é exercido pelo Congresso Nacional, que se compõe da Câmara dos Deputados e do Senado Federal" (BRASIL, [2020]), sendo que a "Câmara dos Deputados compõe-se de representantes do povo, eleitos, pelo sistema proporcional, em cada Estado, em cada Território e no Distrito Federal" (BRASIL, [2020]), e o "Senado Federal compõe-se de representantes dos Estados e do Distrito Federal, eleitos segundo o princípio majoritário" (BRASIL, [2020]).

Neste sistema qualquer uma das Casas Legislativas pode iniciar o processo legislativo, sendo a Casa em que ocorreu a proposição designada por Casa Iniciadora e a outra por Casa Revisora, de modo que um projeto ou proposta apreciada e aprovada em uma delas será enviada a outra para sua revisão. Assim, as duas Casas devem se manifestar sobre a elaboração das leis, a fim de se manter equilíbrio e evitar exceções na produção das leis. Portanto, "a organização legislativa de uma sociedade, desempenha um papel fundamental ao trabalhar para que se saiba $o$ que se deve esperar de todos e de cada um" (NOVELLI, 2008, p. 113).

Adstrito à espécie lei ordinária, compreendida como um ato normativo primário e contém, em regra, normas gerais e abstratas, os projetos de lei (PL) são proposições destinadas a criar uma nova lei ou modificar uma lei existente. Um PL, consoante o art. 61 da CRFB/88, pode ser apresentado por qualquer Deputado ou Senador, comissão da Câmara, do Senado ou do Congresso Nacional, pelo presidente da República, pelo procurador-geral da República, pelo Supremo Tribunal Federal, por tribunais superiores e cidadãos, na forma e nos casos previstos na CRFB/88. Contudo, existem matérias que são de iniciativa exclusiva do Presidente da República, hipóteses previstas no $\S 1^{\circ}$ do artigo 61 da CRFB (BRASIL, [2020]). 
Senso assim, um PL aprovado pelo Congresso Nacional é enviado ao Presidente da República para, em quinze dias, sancioná-lo ou vetá-lo total ou parcialmente. Na hipótese de qualquer veto presidencial, este poderá ser rejeitado, desde que, em sessão conjunta, dentro de trinta dias a contar do seu recebimento, o Congresso Nacional o aprecie e obtenha maioria absoluta de deputados e senadores. Com isso, o PL será enviado para promulgação ao Presidente da República, que terá quarenta e oito horas para fazê-la, caso não faça, a lei será promulgada pelo presidente do Senado Federal e, se este não fizer em igual prazo, pelo seu primeiro vice. Promulgada, a lei será publicada no Diário Oficial da União para que surtam seus efeitos no ordenamento jurídico nacional (BRASIL, [2020]).

Dito isso, aos 16/10/2013, foi apresentado à Câmara dos Deputados o Projeto de Lei ${ }^{\circ}$ 6583 de 2013 (PL 6583/2013) pelo deputado federal à época, Anderson Ferreira, representante de uma bancada evangélica no Congresso Nacional, cuja finalidade é instituir o Estatuto da Família (FERREIRA, 2013). O referido PL, ainda em tramitação na Câmara dos Deputados, inicialmente, teve como relator designado pela Comissão Especial constituída o deputado Ronaldo Fonseca, o qual emitiu parecer favorável à sua tramitação, uma vez que o parlamentar opinou pela constitucionalidade, juridicidade e boa técnica legislativa do referido PL, assim como apresentou substitutivo para adicionar ao PL a proibição de adoção de crianças por casais homossexuais (FONSECA, 2013). Em janeiro de 2015, o PL foi arquivado devido ao fim da legislatura em dezembro de 2014, nos termos do artigo 105 do Regimento Interno da Câmara dos Deputados. Na primeira sessão legislativa de 2015, o PL foi desarquivado e o deputado Diego Garcia foi designado como novo relator, tendo emitido parecer favorável pela tramitação do PL e sua consequente aprovação, bem como apresentou o segundo substitutivo à proposição (GARCIA, 2013).

A redação original do PL 6583/2013, em seu artigo 2º define como família a "entidade familiar como o núcleo social formado a partir da união entre um homem e uma mulher, por meio de casamento ou união estável, ou ainda por comunidade formada por qualquer dos pais e seus descendentes" (FERREIRA, 2013). O segundo substitutivo apresentado pelo deputado relator possui a mesma definição e ainda acrescenta que esse modelo de família é a base da sociedade e credora de proteção social, assim como insere o parágrafo único ao artigo $2^{\circ}$ do $\mathrm{PL}$, para preconizar que "as relações de parentesco na linha ascendente ou colateral, bem como as relações derivadas de direito assistencial, mediante guarda ou tutela, gozam da proteção específica prevista em leis respectivas" (GARCIA, 2013).

Diante deste quadro se extrai que o PL 6583/2013 objetiva legitimar para todos os efeitos legais, inclusive, para ser destinatária de políticas públicas específicas, apenas a união formada por um homem e uma mulher através do casamento ou da união estável e seus eventuais filhos, ou seja, trata-se de um modelo excludente de família heterossexual e monogâmica, também denominada por família nuclear. Porquanto, para além desse modelo ideal de família, o único 
arranjo familiar aceitável é a família monoparental, formada por qualquer um dos pais e seus descendentes, as quais decorrem da viuvez, do divórcio/dissolução da união estável ou da paternidade/maternidade solo, na medida em que estigmatiza todas as demais formatações familiares, como, por exemplo, as uniões homoafetivas, as uniões simultâneas e as uniões poliafetivas (FERREIRA, 2013).

A justificativa do PL se fundamenta no fato de que a família - neste caso compreendida como família nuclear heterossexual monogâmica - funciona como uma espécie de unidade-base da sociedade, de modo que se deve "conferir grande importância à família e às mudanças que a têm alterado a sua estrutura no decorrer do tempo" (FERREIRA, 2013), uma vez que essas alterações seriam responsáveis pelos problemas sociais que emergem na família contemporânea, tais como o uso de drogas e gravidez prematura, posto que, segundo o Deputado Anderson Ferreira, "uma família equilibrada, de autoestima valorizada e assistida pelo Estado é sinônimo de uma sociedade mais fraterna e também mais feliz" (FERREIRA, 2013). A criação do Estatuto da Família, segundo o parlamentar, respalda-se, ainda, na suposta "desconstrução do conceito de família, aspecto que aflige as famílias e repercute na dinâmica psicossocial do indivíduo" (FERREIRA, 2013).

No entanto, diferentemente da idealização do conceito de família apresentado no PL 6583/2013, não se deve atribuir homogeneidade às diversas formas de uniões afetivas, tendo em vista que família não possui um conceito uníssono, à medida que não existe consenso, tampouco uma única definição sobre família, sendo vastas as suas definições por diferentes autores de diferentes áreas de estudo (BOURDIEU, 1996; ENGELS, 2019; FEDERICI, 2019; GOLDANI, 1993; LEVI-STRAUSS, 1983; LÔBO, 2020; VASCONCELOS, 2013; SARTI, 2004). Por isso que a expressão família é passível de descrições, quer dizer, pode-se “[...] descrever as várias estruturas ou modalidades assumidas pela família através dos tempos, mas não a definir ou encontrar algum elemento comum a todas as formas com que se apresenta esse agrupamento humano" (BORSA; FEIL, 2008, p. 2).

Nesse respeito, a família descrita por Lévi-Strauss (1986), por exemplo, consiste na união mais ou menos duradoura, socialmente aprovada, de dois indivíduos de sexos diferentes originado na aliança entre o casal pelo casamento, unidos por laços legais, direitos e obrigações econômicas, religiosas e uma rede de direitos e proibições sexuais e sentimentos, que fundam um lar, procriam e educam seus filhos. Essas uniões funcionam como um sistema de aliança entre grupos diferentes e objetiva a troca entre eles, a fim de disseminar seus ideais para fortalecimento e crescimento de seu grupo, à medida que, por isso, o fundamento da família, nesta ótica, é social, e não natural.

Nessa perspectiva, segundo Sarti (2004), a família envolve um constante confronto entre a identidade que a demarca e a alteridade que força a abertura e traz dinâmica à família, através de um mecanismo de troca entre os diferentes. Portanto, a família não representa uma instituição "natural", mas uma realidade que se constitui pela linguagem e que se define pelos significantes 
que criam os elos de sentido nas relações. Com isso, os laços biológicos unem as famílias porque são significantes e possuem força simbólica, de modo que a família se constitui pela aliança e não pela consanguinidade, por isso, também, não pode sem compreendida como "natural" (SARTI, 2004).

Nesse contexto, a família pode ser pensada como uma construção simbólica entre o mundo exterior e o mundo subjetivo, e, por isso, "cada família constrói seus mitos a partir do que ouve sobre si, do discurso externo internalizado, mas devolve um discurso sobre si que contém também sua própria elaboração, objetivando sua experiência subjetiva" (SARTI, 2004, p. 14). Diz respeito a maneira como os indivíduos, por meio da linguagem, socialmente elaborada e internalizada, constrói a autoimagem e a imagem do mundo exterior, sendo, por conseguinte, um valor que ordena o lugar dos indivíduos na sociedade.

Engels (2019), por outro lado, sob uma perspectiva materialista de família, aduz que a família nuclear que emerge na modernidade, com o advento do modo de produção capitalista, tem como objetivo fundamental a manutenção da propriedade privada por meio da herança. Dessa forma, a produção da vida material explica a forma como as instituições sociais assumem em um determinado contexto, em um determinado período histórico, à medida que o modo de produção da vida material é a dimensão fundamental a partir da qual se pode explicar as instituições sociais, assim como a família.

Federici (2019), também sob uma perspectiva materialista de família, por sua vez, faz conexões entre o início do capitalismo e o período atual, permitindo-se visualizar como a família foi utilizada como instrumento para implantação desse sistema econômico na Europa Ocidental. Assim, uma das estratégias utilizadas para dominar, calar, isolar, destruir os saberes e os corpos das mulheres e retirar a força coletiva feminina foi a criação da família patriarcal burguesa e do ideal de domesticidade por meio do controle da sexualidade feminina e confinamento das mulheres no lar. Dessa forma, percebe-se que a família não consiste em uma instituição natural, independente dos mais variados fatores sociais, mas, sim, confirma que a família representa uma das construções sociais mais bem elaboradas, uma vez que pode funcionar como instrumento regulador e orientador de interesses de grupos dominantes a fim de se obter fins específicos (FEDERICI, 2019).

Diante desses argumentos, percebe-se, de fato, que a forma de organização dos atores sociais enquanto família não se dá de forma homogênea e, tampouco, pode ser pensada como uma instituição natural e generalizada, imune a quaisquer fatores externos. Pelo contrário, infere-se que a idealização de família pelo imaginário humano consiste em uma construção social, variável de acordo com o tempo, o contexto histórico e as mudanças sociais, além de sofrer influência direta de fatores econômicos, políticos e ideológicos. Por isso, os mais diversificados arranjos familiares, sejam eles heterossexuais ou homossexuais, monogâmicos ou poligâmicos, correspondem e detém conteúdo de entidade familiar sem quaisquer distinções com a família 
nuclear defendida pelo PL 6583/2013, sendo que apenas guardam diferenças na sua formulação e organização, atributos que não influenciam no desenvolvimento e manutenção dessas uniões afetivas como socialmente normais e legítimas, muito menos, congregam alguma carga negativa para o pleno desenvolvimento de seus membros (GOLDANI, 1993).

$\mathrm{Na}$ verdade, a ideia das transformações familiares como declínio, em que as formas de família constituídas à margem do modelo de família nuclear burguesa são vistas como desestruturações, conforme Goldani (1993) deve ser refutada, uma vez que a constituição de família de formas alternativas diz respeito às mudanças sociais que afetam direta e indiretamente os indivíduos em sociedade, tais como a demografia, economia e expectativa de vida, de modo que não se pode considerar um modelo hegemônico de família arraigado de preconcepções ideológicas, mas, sim, que suas representações sociais são constantemente revisadas por vários aspectos, confirmando-se a mutabilidade dos arranjos familiares.

Dessa forma, em que pese a naturalização da família nuclear heterossexual monogâmica pelo PL 6583/2013, os sujeitos sociais se organizam de diversas formas como família, o que não é óbice para sua leitura como tal e, sequer, representam modelos inferiores e/ou desestruturados de família. Isso pois, conforme preconiza Bourdieu (1996, p. 135), "a família é certamente uma ficção, um artefato social, uma ilusão no sentido mais comum do termo, mais uma 'ilusão bem fundamentada' já que, produzida e reproduzida com a garantia do Estado, ela sempre recebe do Estado os meios de existir e subsistir".

Além disso, deve-se atentar, também, para o fato de que o constituinte originário contemplou o princípio do pluralismo familiar, uma vez o caput do artigo 226 da CRFB/88 "é, consequentemente, cláusula geral de inclusão da família, não sendo admissível excluir qualquer entidade que preencha os requisitos de afetividade, estabilidade e ostensibilidade" (LÔBO, 2020, p. 95). Por isso, "tem-se que a família, antes fundada no patrimônio, hoje, vê-se regida pelo eudemonismo (a busca da felicidade), solidariedade e respeito à dignidade humana de cada membro" (VIEGAS; POLI, 2015, p. 58). Logo, a limitação da família nuclear heterossexual monogâmica como forma exclusiva de arranjo familiar pelo PL 6583/2013 contradiz e viola a própria $\mathrm{CRFB} / 88$, posto que com seu advento, “o Brasil inaugurou o paradigma do Estado Democrático de Direito, fundado nos princípios e regras que visam realizar e promover a dignidade humana, alterando, essencialmente, o conceito de família, ampliado dia a dia" (VIEGAS; POLI, 2015, p. 56).

Portanto, diferentemente da justificativa apresentado no PL 6583/2013, a pluralidade dos arranjos familiares presentes na contemporaneidade não representam desvios de condutas passíveis de correção ou opressão, mas, sim, decorrem do fato de que no século XXI, em regra, os atores sociais possuem maior liberdade para se relacionar afetivamente na sociedade atual, seja pela maior aceitação do corpo social ou pelo reconhecimento do Estado de arranjos familiares alternativos, mesmo que, muitas vezes, ainda é exigido que os sujeitos sociais sigam modelos pré- 
determinados de família para que sua união seja protegida por normas e destinatárias de políticas públicas familiares específicas (GIDDENS, 2002).

Nessa perspectiva, amparado na Teoria das Representações Sociais (MOSCOVICI, 2011; JODELE, 2001), o presente artigo, por meio do método da revisão bibliográfica e da análise documental, tem como objetivo analisar as representações sociais de família no PL 6583/2013 (Estatuto da Família), mais precisamente em sua redação original e na justificativa do deputado Anderson Ferreira, uma vez que o referido PL conceituou para fins legais e de proteção estatal apenas a família nuclear monogâmica heterossexual, mesmo ante a existência de uma diversidade de arranjos familiares que não diferentes desse modelo, mas apenas se formam e existem de maneira diferente do ideal de família da proposição legislativa objeto de estudo. Senso assim, o PL 6583/2013 consiste no corpus de análise deste trabalho.

\section{Procedimentos Metodológicos}

O presente artigo utilizou da pesquisa documental e da revisão bibliográfica como estratégias metodológicas. O objeto de análise deste trabalho é o projeto de lei 6583 de 2013, também denominado por Estatuto da Família, notadamente a redação original do PL e a justificativa apresentada pelo Deputado Anderson Ferreira, que foram utilizadas como fontes primárias para a extração de dados.

A escolha pela pesquisa documental como método de coleta e análise de dados ocorreu tendo em vista que os documentos "não são apenas uma fonte de informação contextualizada, mas surgem em um determinado contexto e fornecem informação sobre esse mesmo contexto" (LÜDKE; ANDRÉ, 1986, p. 39), de modo que viabilizou perscrutar qual a representação social de família no PL 6583/2013 objeto de análise.

Para tanto, realizou-se uma análise de conteúdo, compreendida como "uma categoria de procedimentos explícitos de análise textual para fins de pesquisa social" (BAUER, 2002, p. 191), ou seja, trata-se de "uma técnica para produzir inferências de um texto focal para seu contexto social de maneira objetiva" (BAUER, 2002, p. 191). Por fim, foi realizada uma análise qualitativa descritiva, com aporte na literatura sobre o tema, especialmente, em trabalhos de autores clássicos que estudam famílias (BOURDIEU, 1996; BRUSCHINI, 2000; ENGELS, 2019; FEDERICI, 2019; GOLDANI, 1993; LEVI-STRAUSS, 1983; SARTI, 2004) e em textos selecionados através da busca na plataforma "Google Acadêmico" pelas palavras-chaves "família", "representações sociais", "PL 6583/2013” e "Estatuto da Família", cumulativamente, no total de 05 (cinco) trabalhos específicos (PEREIRA, 2015; VASCONCELLOS, 2013; CARDOSO et al., 2020; BELFORT et al., 2015, LOBO, 2020). 


\section{Representações Sociais de Família no Estatuto da Família}

As proposições legislativas emanam da percepção humana acerca de seu entendimento sobre os fatos sociais e a consequente necessidade de sua positivação no ordenamento jurídico, a fim de orientar e regular o comportamento dos indivíduos na sociedade em que se encontra inserido. Assim, desde a apresentação de um PL para criar ou modificar uma norma, são vários os argumentos que subsidiam seu conteúdo, notadamente, aqueles advindos da mentalidade formada pelas representações sociais de um indivíduo/grupo responsável por sua apresentação e pelos seus defensores (CANDAU, 2005).

Nessa acepção, o discurso sustentado deputado Anderson Ferreira na apresentação do PL 6583/2013, mais precisamente na sua redação original e na sua justificativa, os quais constituem o corpus desta pesquisa, compõem um rico conteúdo para que se verifique e analise quais as Representações Sociais (RS) da família são evocadas e mobilizadas, tendo em vista que "as representações sociais são entidades quase que tangíveis. Elas circulam, cruzam-se e se cristalizam incessantemente através da fala, de um gesto, de um encontro, em nosso universo cotidiano" (MOSCOVICI, 2011, p. 41).

Posto isso, a Teoria das Representações Sociais se faz pertinente para estudar a família enquanto categoria analítica a partir do discurso assumido pelo deputado responsável pela proposição legislativa na tentativa de se convencer os demais parlamentares para a aprovação do PL 6583/2013, à medida que esse método de análise possibilita compreender como se estruturam os conteúdos da RS da família pelo parlamentar, assim como oportuniza que se apreenda como este percebe as transformações da família ao longo do tempo (ARRUDA, 2002). Ou seja, este método permite que se trabalhe com a memória social sobre a família e as transformações das representações sociais (RSs) da família no tempo e no espaço (CANDEU, 2005).

Isto pois, os indivíduos representam para dialogarem com base em uma reunião de sentidos consensuais - função de saber. Tais sentidos funcionam como orientações preliminares da maneira de como um grupo deve agir ante um objeto específico - função de orientação -, assim como viabilizam que estes comportamentos sejam justificados posteriormente - função justificadora. Além disso, as representações também podem atuar como estrutura para a elaboração e a proteção da identidade social dos membros de determinado grupo - função identitária (ABRIC, 2000).

Nessa perspectiva, as RSs são uma forma de conhecimento, socialmente elaborada e partilhada, tendo uma visão prática e concorrendo para a construção de uma realidade comum a um conjunto social (SÊGA, 2000). Isso significa que as RSs, como um processo mental, carregam sempre um sentido simbólico. Em vista disso, segundo Sá (1998, p. 68), a RS é “uma modalidade de saber gerada através da comunicação na vida cotidiana, com a finalidade prática de orientar os comportamentos em situações sociais concretas" em que o estranho é incorporado.

Sendo assim, a partir do contato com a família, suas transformações e informações acerca 
dela, iniciar-se-ão dois processos formadores de sua representação social, quais sejam, a objetivação e a ancoragem (JODELET, 2001). Nesses processos se articulam a atividade cognitiva, mobilização afetiva e as condições sociais. Com isso, "as pessoas dão sentido ao objeto, ancorando-o nos sistemas de referências já possuídos e vão modificando suas estruturas para se adaptar ao novo e às demandas da realidade social" (VASCONCELOS, 2013, p. 42).

Dessa forma, o processo de objetivação "implica uma construção seletiva e uma descontextualização, por meio das quais apenas alguns elementos do objeto são filtrados e retidos, dependendo de significados pré-existentes frutos da inserção grupal" (VASCONCELOS, 2013, p. 42). Já o processo de ancoragem diz respeito a "assimilação do novo elemento num sistema de categorias familiares mediante alguns ajustes. O objeto é integrado num sistema de valores, denominado e classificado de acordo com a inserção social" (VASCONCELOS, 2013, p. 42). Ou seja, "o objeto novo é reajustado para que se enquadre em uma categoria conhecida adquirindo características dessa categoria” (SANTOS, 2005, p. 33).

Sendo assim, a integralidade das informações que se acessa sobre família é selecionada e são preservados, sobretudo, os ideais condizentes com os valores, as práticas e as imagens compartilhadas por um grupo específico num dado momento (JODELET, 2001). Portanto, o discurso assumido pelo Deputado Anderson Ferreira para aprovação do PL 6583/2013 compreende uma teoria que naturaliza a instituição social família, fundada a partir da exclusão dos diferentes arranjos familiares em detrimento de uma idealização de família que se pretende legalizar como modelo exclusivo, conforme será analisado nessa sequência.

\section{Análise, Discussões e Resultados do PL 6583/2013 e sua Justificativa}

A apresentação do PL 6583/2013 à Câmara dos Deputados foi realizada pelo Deputado Federal à época Anderson Ferreira, natural de Recife/PE e filiado ao Partido Liberal (PL) designado até 2019 por Partido da República (PR). O parlamentar, que exerceu seu mandato até janeiro 2017, quando renunciou ao cargo de Deputado para assumir o mandato de Prefeito de Jaboatão dos Guararapes/PF, é evangélico, membro da denominação religiosa Assembleia de Deus, e enquanto Deputado integrava às Frentes Parlamentares Evangélicas, Mista da Família e Apoio à Vida.

Diante desse quadro, primeiramente, pode-se constatar a função identitária da RS da família para o parlamentar com a mentalidade do grupo religioso que integra. Dessa forma, sua RS da família corresponde a ideologia religiosa de seu grupo e, por isso, compreende a família como uma instituição "natural" e sagrada, tendo em vista que para os evangélicos da congregação Assembleia de Deus, apenas a união afetiva formada por duas pessoas de sexos diferentes e seus descendentes pode ser considerada como família, ao passo que todas as demais formatações familiares são marginalizadas por esse grupo devido ao fato de contradizerem aos seus dogmas (PEREIRA, 2015). 
Tanto é que a definição de família conforme o artigo $2^{\circ}$ do PL 6583/2013 preconizada esse ideal, uma vez o conceito de família parte da união entre um homem e uma mulher excluindo-se as uniões afetivas homoafetivas, poligâmicas e simultâneas -, fundada no casamento ou na união estável - desconsiderando-se as uniões que ainda não foram investidas de legalidade pelo Estado. Com isso, o parlamentar pretende instituir um conceito fechado de família no singular quando não contempla as mudanças em sua estrutura como parte da evolução social e, por conseguinte, inviabiliza o reconhecimento e a proteção de outros arranjos familiares, justamente como ocorre no ideário cristão de família, confirmando-se expressa religiosidade nos assuntos políticos e evidenciando-se os elementos da formação de sua RS da família (PEREIRA, 2015).

Dessa maneira, a intencionalidade da redação original do PL pelo Deputado Anderson Ferreira em conceituar família de forma excludente a partir de uma mentalidade religiosa, objetiva legalizar o ideário de família do grupo que ele integra, ou seja, trata-se da função justificadora da RS da família que ele compactua (ABRIC, 2000). Isso significa que a partir da leitura da família sob a ótica do cristianismo, a pretensão do deputado é dar roupagem legal a sacralidade dos relacionamentos, na medida em que se assenta na complementaridade dos corpos masculinos e femininos e na associação cristã do sexo como procriação, na tentativa de desqualificar as relações homossexuais e garantir a heteronormatividade e a monogamia (PEREIRA, 2015).

Nessa perspectiva, verifica-se que a RS da família no PL 6583/2013 traz em seu processo de objetivação elementos do ideal de família cristã, formada pela união sacralizada entre um homem e uma mulher e seus eventuais filhos. Esses elementos são descontextualizados da ideologia religiosa para que sejam assimilados como instituição "natural" no contexto de um Estado laico. Todavia, nota-se um ideal de família pautada na heteronormatividade, na maternidade compulsória e na divisão sexual do trabalho (ENGELS, 2019). Portanto, no processo de ancoragem da RS da família no PL 6583/2013, a família cristã se reajusta a uma "família natural", como uma espécie de instituição independente dos diversos fatores sociais, dos contextos e das mudanças sociais.

Sendo assim, constata-se que a RS da família no PL 6583 tem como finalidade prática a orientação dos indivíduos a se comportarem em sua vida privada respeitando o padrão de família nuclear monogâmica heterossexual para que tenham acesso às políticas públicas específicas para a família, à medida que estigmatiza os demais arranjos familiares (GOFFMAN, 2004). Melhor dizendo, trata-se da implantação do ideal de um grupo político (CANDAU, 2005), neste caso, os evangélicos, sobre toda a coletividade social, tendo em vista que "a lei assume a função de norma, de mecanismo regulador e corretivo" (VASCONCELOS, 2013, p. 41). Porquanto, percebe-se que a idealização da família está inserida nos jogos de poder "que se produzem nas relações sociais (sexuais, familiares, de conhecimento, econômicas) e se refere às estratégias que originam essas forças e as cristalizam nos aparelhos estatais, na formulação das leis e nas hegemonias sociais" 
(VASCONCELOS, 2013, p. 39).

Dessa forma, ainda se pode demonstrar a função identitária da RS de família no PL 6583/2013 (ABRIC, 2000), tendo em vista que o artigo 10 da proposição legislativa preconiza que "os currículos do ensino fundamental e médio devem ter em sua base nacional comum, como componente curricular obrigatório, a disciplina ‘Educação para família' (FERREIRA, 2013)”. Ou seja, a RS de família atua como estrutura para a elaboração e a proteção da identidade social dos membros da frente parlamentar evangélica da Câmara dos Deputados, uma vez que pretende atribuir status legal a sua mentalidade para manutenção de seus ideais a partir da interferência pedagógica na socialização primária dos indivíduos (PEREIRA, 2015).

Ademais, considerando-se que a CRFB/88 garante a liberdade individual como direito fundamental, bem como introduziu o princípio da pluralidade familiar, tornar uma RS da família baseada no imaginário cristão em lei, por um lado, mostra-se claramente contrário aos preceitos constitucionais, uma vez que funciona como mecanismo legitimador de preconceitos e desigualdades (VIEGAS; POLI, 2015). Por outro lado, ignorar que os atores se organizem de várias formas como família e, como retaliação, deslegitimar essas uniões de serem destinatárias de políticas públicas, nada mais é do que reafirmar a interferência de grupos específicos no mundo privado (PEREIRA, 2015).

Demais disso, o parlamentar cita em sua justificativa que a "desconstrução" do conceito de família repercute na dinâmica psicossocial do indivíduo, ao aduzir que:

Tenho feito do meu mandato e de minha atuação parlamentar instrumentos de valorização da família. Acredito firmemente que a felicidade do cidadão está centrada sobretudo na própria felicidade dos membros da entidade familiar. Uma família equilibrada, de autoestima valorizada e assistida pelo Estado é sinônimo de uma sociedade mais fraterna e também mais feliz (FERREIRA, 2013, p. 7).

Sendo assim, quando o deputado justifica sua proposição legislativa na desvirtuação do conceito tradicional de família, fica ainda mais clara a intenção de marginalizar os demais arranjos familiares a fim de garantir a perpetuação de seus ideais, uma vez que desconsidera os processos sociais que perpassam pela família e atribui anormalidade aos modelos de família que se formam a partir de outros referenciais (BOURDIEU, 1996). Inclusive, o deputado atribui os problemas sociais da família contemporânea, como uso de drogas e gravidez na adolescência, às famílias que não seguem seu modelo de RS da família, o que justifica a criação de políticas públicas do Estado direcionadas exclusivamente ao seu ideal de família.

No entanto, observa-se que esse discurso diz respeito a estratégias de reafirmação de uma mentalidade e restrição de formação de identidades (CANDAU, 2005). Portanto, em conformidade com Federici (2019), deve-se considerar que a família não consiste em uma instituição natural, independentemente dos variados fatores sociais, mas, sim, confirma que a família representa uma das construções sociais mais bem elaboradas, uma vez que pode funcionar 
como instrumento regulador e orientador de interesses de grupos dominantes a fim de se obter fins específicos.

Justamente por isso, faz-se imprescindível interpretar as diferentes condutas vinculares, os papéis multidimensionais e os diferentes elementos constituintes de família. Nessa ótica, devese apreender uma ideia de pluralismo e multiplicidade familiar, de modo a se abster de uma compreensão singular de família. Isso, pois, a "estrutura familiar, sendo diversificada, é mesclada por influências históricas e por uma organização específica interna de cada grupo familiar" (CARDOSO et al., 2020, p. 30), razão pela qual não é possível compreender a família em um único modelo.

Conforme Goldani (1993), as mudanças nas estruturas familiares não devem ser vistas como declínio e, muito menos, como uma forma de desestruturação familiar, uma vez que a instituição família nada mais é do que um processo de construção social que sofre influência direta de fatores sociais. Logo, compreender a família como uma constante linear, imutável, é ignorar o próprio desenvolvimento dos sujeitos sociais e suas adaptações às diversas circunstâncias que repercutem na esfera privada da vida, de modo que o modelo de família nuclear diz respeito a uma forma de família que se mostrou interessante para sua época e, erroneamente, tem sido difundido como um ideal de família (BOURDIEU, 1996)

Nesse ponto, Sarti (2004) propõe que a família seja pensada como uma construção simbólica entre o mundo exterior e o mundo subjetivo, e, por isso, "cada família constrói seus mitos a partir do que ouve sobre si, do discurso externo internalizado, mas devolve um discurso sobre si que contém também sua própria elaboração, objetivando sua experiência subjetiva" (SARTI, 2004, p. 14). Trata-se da maneira como os indivíduos, por meio da linguagem, socialmente elaborada e internalizada, constrói a autoimagem e a imagem do mundo exterior, sendo, por conseguinte, um valor que ordena o lugar dos indivíduos na sociedade.

A família, portanto, não é natural, mas, sim, social, mesmo ante a tentativa de naturalização das relações familiares a partir de definições socialmente instituídas pelos dispositivos jurídicos, médicos, psicológicos, religiosos e pedagógicos. Estes referenciais “constituem os 'modelos' do que é e deve ser a família, fortemente ancorados numa visão de família como uma unidade biológica constituída segundo as leis da 'natureza' (SARTI, 2014, p. 17)”. Com isso, institui-se "um 'dever ser' no horizonte, referência positiva a partir da qual todo o resto torna-se 'desvio' ou 'anormalidade', quando não, 'patologia' (SARTI, 2014, p. 17)”, sendo que, na verdade, trata-se de um discurso normativo de um ideal a ser seguido.

Dessa forma, evidencia-se que o conceito de família defendido no PL 6583/2013, além de desrespeitar as garantias individuais, sobretudo, a liberdade individual, não contempla todas as transformações e as mudanças que ocorrem na sociedade, uma vez que objetiva naturalizar um modelo de família a fim de se legitimar a estigmatização dos mais diversos arranjos familiares que compõem a realidade social (LOBO, 2020). Conforme demostram Cardoso et al. (2020), a 
descrição de família na contemporaneidade é holística, uma vez que se faz necessário incluir, refletir os contextos e as vivências de suas diferentes formatações.

Portanto, a RS social da família no PL 6583/2013 diz respeito a uma ideologia religiosa da frente parlamentar evangélica do Congresso Nacional, que visa demonizar as mais variadas formas de uniões afetivas presentes na sociedade contemporânea e reafirmar a família cristã como uma instituição natural a fim de garantir que a mentalidade desse grupo político seja confirmada e amparada pelo Estado, de modo que se estigmatizam os demais arranjos familiares no contexto de um Estado Democrático de Direito.

Antes esses argumentos, o PL 6583/2013, em verdade, busca definir família de maneira excludente com a finalidade de se garantir a hegemonia da concepção de uma ideologia religiosa através da intervenção direta do Estado no espaço privado. Sendo assim, a RS da família parte da mentalidade de um grupo político específico, o qual desconsidera as mais diversas mudanças na sociedade e, principalmente, ignora a liberdade da construção da subjetividade humana a partir de seus referenciais, na medida em que atribui os problemas familiares que emergem na contemporaneidade aos arranjos familiares que não se enquadram no seu modelo de referência (BELFORT et al. 2015). Afinal, a RS da família para esse grupo político é feita de memória e daquilo que é transmitido entre gerações, uma vez que se pretende garantir a mentalidade desse grupo através de uma lei.

\section{Conclusão}

A família representa uma instituição social de grande destaque por ser uma das mais antigas e fundamentais à organização social, e, por isso, no imaginário social, prevalece uma predisposição de pensá-la como algo natural e generalizado. Todavia, como demonstrado neste trabalho, consta-se que esta idealização de família, na verdade, consiste em uma construção social, variável de acordo com o tempo, o contexto histórico e as mudanças sociais, além de sofrerem influência direta de fatores econômicos, políticos e ideológicos, sendo, portanto, um equívoco atribuir homogeneidade às diversas formas de uniões afetivas, como ocorre no PL 6583/2013 que tramita na Câmara dos Deputados.

Sendo assim, a partir desta análise, propõe-se a pensar a instituição família sempre no plural, respeitando-se suas diferentes estruturações, posto que as relações amorosas não podem ser determinadas em sua integralidade em um modelo exclusivo de família e, muito diferente do que é defendido no PL 6583/2013, jamais conseguiria o legislador abarcar todas as formas de se constituir família em um único modelo, uma vez os fatos sociais sempre as precedem e os diversos arranjos familiares não são inferiores à formatação nuclear de família. Na verdade, os diferentes arranjos familiares podem ser consolidados de tantas maneiras que afastar uma união afetiva da caracterização de família constituída por não se enquadrar em um modelo de família dominante é negar o próprio desenvolvimento social, uma vez que a mutação das formas de se relacionar 
afetivamente se dá por um processo de construção de autonomia e respeito as escolhas subjetivas dos sujeitos sociais.

Ante esses argumentos, pode destacar a contribuição deste trabalho em demonstrar que o conceito de família previsto no PL 6583/2013 representa a RS da família para a Frente Parlamentar Evangélica da Câmara, em que o deputado Anderson Ferreira é integrante, está baseada nos elementos da sacralidade das uniões afetivas, na heteronormatividade e na monogamia. E, por isso, pode-se considerar que a finalidade da proposição legislativa consiste em um mecanismo de controle de comportamentos sociais e em uma tentativa de reafirmação da família enquanto instituição natural, uma vez que se pretende regular e orientar os atores sociais a seguirem um padrão excludente de família para serem destinatários de políticas públicas.

Por fim, este trabalho se alinha a perspectiva da literatura utilizada para sua construção, mas se diferencia deles na medida em demostra a interferência de grupos políticos, neste caso, os evangélicos congregados da Assembleia de Deus, na organização do Estado a fim de manter homogeneidade nas relações sociais a partir de seus referenciais. Evidenciou-se a tentativa de perpetuação da mentalidade do aludido grupo político em valer do Poder Legislativo para controlar as individualidades dos sujeitos sociais, numa demasiada interferência na esfera privada da vida.

\section{Agradecimentos}

O autor deste artigo é financiado com bolsa da Fundação de Amparo à Pesquisa do Estado de Minas Gerais (FAPEMIG) em sua pesquisa (2020-2022) de Mestrado em Economia Doméstica na Universidade Federal de Viçosa (UFV).

\section{Referências}

ABRIC, Jean-Claude. A abordagem estrutural das representações sociais. In: MOREIRA, A. S. P.; OLIVEIRA, D. C. de (Orgs.). Estudos interdisciplinares de representação social. Goiânia: AB Editora, 2000.

ARENDT, Hannah. Origens do Totalitarismo Antissemitismo, imperialismo, totalitarismo. Tradução de Roberto Raposo. São Paulo: Companhia de Bolso, 2012.

ARRUDA, Ângela. Teoria das representações sociais e teorias de gênero. Cadernos de Pesquisa, n. 117, p. 127-147, 2002. Disponível em: http://www.scielo.br/pdf/\%0D/cp/n117/15555.pdf. Acesso em: 18 jan. 2021.

BAUER, Martin W. Análise de conteúdo clássica: uma revisão. In: M. W. Bauer e G. Gaskell (Eds.). Pesquisa qualitativa com texto, imagem e som: um manual prático. Petrópolis: Vozes, 2002.

BELFORT, Pollyanna Brandão et al. Representações sociais de família no contexto do acolhimento institucional. Psicologia: Teoria e prática, v. 17, n. 3, p. 42- 51, 2015. Disponível em: http://pepsic.bvsalud.org/scielo.php?script=sci_arttext\&pid=S1516-36872015000300004. Acesso em: 04 fev. 2021.

BORSA, Juliana Callegaro; FEIL, Cristiane Friedrich. O PAPEL DA MULHER NO 
CONTEXTO FAMILIAR: UMA BREVE REFLEXÃO. O portal dos Psicólogos, p. 1-12, jun. 2008. Disponível em: https://www.psicologia.pt/artigos/textos/A0419.pdf. Acesso em: $14 \mathrm{dez}$. 2020.

BOURDIEU, Pierre. Apêndice: o espírito de família. In: BOURDIEU, Pierre. Razões práticas. Campinas: Papirus, 1996, p. 124-135.

BRASIL. [Constituição (1988)]. Constituição da República Federativa do Brasil de 1988. Brasília, DF: Presidência da República, [2020]. Disponível em: http://www.planalto.gov.br/ccivil_03/constituicao/constituicaocompilado.htm. Acesso em: 18 jan. 2021.

CANDAU, Joël. Antropologia da Memória. Tradução de Míriam Lopes. Lisboa:

Instituto Piaget, 2005.

CARDOSO, Alexandra Sombrio et al. Representações sociais da família na contemporaneidade: uma revisão integrativa. Pensando Família. Porto Alegre, v. 24, n. 1, p. 29-44, jun. 2020. Disponível em: http://pepsic.bvsalud.org/scielo.php?script=sci_arttext\&pid=S1679494X2020000100004\&lng=pt\&nrm=iso. Acessos em: 06 jan. 2021.

ENGELS, Friedrich. A origem da família, da propriedade privada e do Estado. Tradução de Nélio Schneider. São Paulo: Boitempo Editorial, 2019.

FEDERICI, Silvia. Mulher e caça às bruxas. São Paulo: Boitempo, 2019.

FERREIRA, Anderson. Projeto de Lei n. 6583/2013. Dispõe sobre o Estatuto da Família e dá outras providências. Brasília: Câmara dos Deputados, 16 out. 2013. Disponível em: https://www.camara.leg.br/proposicoesWeb/prop_mostrarintegra?codteor=1379862\&filename= Tramitacao-PL+6583/2013. Acesso em: 06 jan. 2021.

FONSECA, Ronaldo. Parecer do Relator n. 1 PL658313. In: FERREIRA, Anderson. Projeto de Lei n. 6583/2013. Dispõe sobre o Estatuto da Família e dá outras providências. Brasília: Câmara dos Deputados, 16 out. 2013. Disponível em: https://www.camara.leg.br/proposicoesWeb/prop_mostrarintegra?codteor=1287153\&filename= Tramitacao-PL+6583/2013. Acesso em: 06 jan. 2021.

GARCIA, Diego. Parecer do Relator n. 2 PL658313. In: FERREIRA, Anderson. Projeto de Lei n. 6583/2013. Dispõe sobre o Estatuto da Família e dá outras providências. Brasília: Câmara dos Deputados, 16 out. 2013. Disponível em: https://www.camara.leg.br/proposicoesWeb/prop_mostrarintegra?codteor=1379862\&filename $=$ Tramitacao-PL+6583/2013. Acesso em: 06 jan. 2021.

GIDDENS, Anthony. Modernidade e identidade. Tradução de Plínio Dentzien. Rio de Janeiro: Zahar, 2002.

GOFFMAN, Erving. Estigma: notas sobre a manipulação da identidade. Tradução de Mathias Lambert. Sabotagem, 2004. Disponível em: https://we.riseup.net/assets/212390/estigmaervinggoffman-140509193459-phpapp01.pdf. Acesso em: 18 jan. 2021.

GOLDANI, Ana Maria. As famílias no Brasil contemporâneo e o mito da desestruturação. In: Cadernos Pagu, v.1, n. 1, p. 68-110, 1993.

JODELET, Denise. Representações sociais: um domínio em expansão. In: JODELET, Denise. As representações sociais. Rio de Janeiro: EDUERJ, 2001.

LEVI-STRAUSS, Claude. A família. In: O Olhar distanciado. Lisboa: Edições 70, 1983, p. 69-98.

LÔBO, Paulo. Direito Civil: famílias. São Paulo: Saraiva, v. 5, 10. ed., 2020.

LÜDKE, Menga; ANDRÉ, M. E.D.A. Pesquisa em educação: abordagens qualitativas. São Paulo: EPU, 1986. 
MOSCOVICI, Serge. A representação social da psicanálise. Rio de Janeiro: Zahar, 2011.

NOVELLI, Pedro Aparecido. A crítica de Hegel ao conceito de lei em Kant. Revista

Eletrônica Estudos Hegeliano, n. 9, dez. 2008, p. 101-116. Disponível em:

https://www.hegelbrasil.org/reh9/novelli.pdf. Acesso em: 18 jan. 2021.

PEREIRA, Amanda Barros Seabra. Família e gênero no Congresso Nacional: uma análise da atuação dos parlamentares religiosos na tramitação do Estatuto da Família. 2015. Monografia (Graduação em Ciência Política) - Universidade de Brasília, Brasília, 2015. Disponível em: https://bdm.unb.br/handle/10483/12720. Acesso em: 16 dez. 2020.

SÁ, Celso Pereira de. de. A construção do objeto de pesquisa em Representações Sociais. Rio de Janeiro: EdUERJ, 1998.

SANTOS, Maria de Fátima de Souza. A Teoria das Representações Sociais. In: SANTOS, Maria de Fátima de Souza; ALMEIDA, Leda Maria de (Orgs.). Diálogos com a Teoria das Representações Sociais. Recife: UFPE, 2005.

SARTI. Cynthia Andersen. A família como ordem simbólica. Psicologia USP, v. 15, n. 3, p. 11 28, 2004. Disponível em: http://www.scielo.br/pdf/pusp/v15n3/24603.pdf. Acesso em: 26 jan. 2021.

SÊGA, Rafael Augustus. O conceito de representação social nas obras de Denise Jodelet e Sege Moscovici. Anos 90, Porto Alegre, n. 13, julho de 2000. Disponível em: www.ufrgs.br/ppghist/anos90/13/13art8.pdf. Acesso em: 18 jan. 2021.

VASCONCELLOS, Karina de Mendonça. A representação social da família: desvendando conteúdos e explorando processos. 2013. Tese (Doutorado em Psicologia Social, do Trabalho e das Organizações) - Universidade de Brasília, Brasília, 2013. Disponível em: https://repositorio.unb.br/handle/10482/13272. Acesso em: 05 jan. 2021.

VIEGAS, Cláudia Maria de Almeida; POLI, Leonardo Macedo. O reconhecimento da família poliafetiva no Brasil: uma análise à luz dos princípios da dignidade humana, autonomia privada, pluralismo familiar e isonomia. Revista Duc In Altum Cadernos de Direito, v. 7, n. 13, p. 5499, set.-dez. 2015. Disponível em:

https://faculdadedamas.edu.br/revistafd/index.php/cihjur/article/view/15. Acesso em: 12 jan. 2021.

Artigo submetido em: 2021-05-28

Artigo aceito em: 2021-06- 25 